\title{
Branchial Cleft Excision in the Adult Population
}

\author{
Joseph G Brungardt, MD, Adam C Kahle, MD* and Kurt P Schropp, MD
}

Department of Surgery, University of Kansas, USA

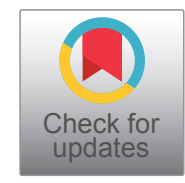

\begin{abstract}
Purpose: Branchial clefts are most often associated with the pediatric population but can also affect adults. The adult population undergoing branchial cleft excision is poorly described. This study sought to describe the population and outcomes of those undergoing branchial cleft excision.
\end{abstract}

Materials and methods: An analysis of the American College of Surgeons National Surgical Quality Improvement Program (ACS NSQIP) database (2015 to 2018) was performed, capturing patients with a postoperative diagnosis of a branchial cleft malformation. Patients were stratified into two groups of superficial or deep excision based upon procedure code. Demographics, perioperative variables, surgeon specialty, lesion type, and outcomes were compared between the two groups.

Results: A total of 399 patients undergoing surgical treatment of branchial cleft anomalies were captured. Most of these patients were white $(66.67 \%)$, female $(53.88 \%)$ and middle-aged ( $36.89 \pm 15.42$ years). For those undergoing superficial excision versus deep excision, there were no significant differences in demographics, comorbidities, or perioperative variables. Unsurprisingly, mean operative time was longer in the deep excision group ( $90 \pm 50$ versus $73 \pm 52$ minutes for superficial excision, $p=0.0013$ ). There were no deaths at 30 days. Length of stay, readmission rate, wound infection, and discharge destination were similar among both groups.

Conclusions: Given the low rate of complications associated with branchial cleft excision, differences between surgical specialty, pathology, or procedural type can be difficult to distinguish. Based on these data, branchial cleft excision is a safe procedure with little clinical difference between excision of superficial or deep lesions.

\section{Introduction}

Branchial cleft anomalies are typically associated with the pediatric population, representing approximately $20 \%$ of pediatric head and neck lesions [1-3]. In the adult population, head and neck lesions most commonly represent cancer, either primary or metastatic [4]. Lateral cystic neck masses have been thought to be most commonly caused by branchial clefts anomalies. While neoplastic, other cystic processes, infectious, and reactive processes can mimic branchial cleft anomalies [3,5-7]. Though biopsy can aid in the differential, complete excision is often recommended to rule out neoplasm [8].

Branchial cleft excision has been well described in the pediatric population; however, little data exists regarding the demographics or perioperative outcomes in the adult population. Branchial cleft anomalies are not necessarily comparable to other head and neck lesions undergoing similar procedures, and they may not have had radiation or chemotherapy like cancerous lesions. Case reports and small institutional cohorts exist, but even these are scarce [9-11]. Workup may include biopsy or imaging, and treatment in adults is typically surgical excision due to the risk of infection or an increase in size [5].
The present study's objectives were to describe a national population of patients undergoing excision of branchial cleft malformations. The aim was not only to define the demographics but also to describe and compare surgical outcomes of superficial and deep excision of branchial cleft lesions. We hypothesized that the length of operation in the deep excision group would be longer. Still, otherwise, clinical outcomes, as they are available in NSQIP, would be similar between superficial and deep excision.

\section{Materials and Methods}

\section{Clinical data}

Data used was from the American College of Surgeons National Quality Surgical Improvement Program (ACS NSQIP),

*Corresponding author: Adam C Kahle, MD, Department of Surgery, The University of Kansas, 4000 Cambridge, M/S 2005 Kansas City, KS 66160, USA Tell: 913-588-6124

Accepted: January 09, 2021

Published online: January 11, 2021

Citation: Brungardt JG, Kahle AC, Schropp KP (2021) Branchial Cleft Excision in the Adult Population. J Head Neck Surg 3(1):113-118

Copyright: (C) 2020 Brungardt JG, et al. This is an open-access article distributed under the terms of the Creative Commons Attribution License, which permits unrestricted use, distribution, and reproduction in any medium, provided the original author and source are credited. 
years 2015 to 2018 [12]. This database contains patient- level, aggregate data, and is compliant with the Health Insurance Portability and Accountability Act as it does not identify hospitals, physicians, or patients. This data is free to ACS NSQIP participating hospitals. The benefit of this particular national dataset is that it collects more granular data of specific perioperative risk factors and outcomes. The Institutional Review Board of the University of Kansas Medical Center approved this study.

\section{Participant classifications}

The study included all patients 18 years of age and older with a postoperative diagnosis of branchial cleft malformation, according to The International Classification of Diseases ninth and tenth editions. These codes were 744.4, 744.41, 744.42, 744.43, 744.46, 744.47, 744.49, Q18.0, Q18.1, or Q18.2. Patients were then stratified into two groups, those who underwent superficial excisional procedures (CPT 42810) or deep excisional procedures (CPT 42815) by current procedural terminology coding. The age, sex, race, comorbidities, perioperative variables, elective operation, wound class, preoperative laboratory values, admission quarter, mortality, length of operation, length of stay, discharge destination, surgeon specialty, and postoperative outcomes, such as readmission and return to the operating room, as well as complications such as deep vein thrombosis or wound infection, were included in the analysis as available in NSQIP.

\section{Statistical analysis}

Baseline characteristics were compared by the chi-square test or two-sample t-test, using Fischer's exact test where necessary. Postoperative outcomes were analyzed utilizing the same tests. Multivariable regression modeling was not carried out due to the low sample size and homogeneity between preoperative variables. Statistical analysis and data management were performed using SPSS (IBM Corp. IBM SPSS Statistics for Windows, Version 23.0. Armonk, NY: IBM Corp) and Excel (from Microsoft version 16.32). Significance is indicated by $p<0.05$.

\section{Results}

A total of 399 patients were included in the study, with 147 (36.84\%) undergoing superficial excision and 252 (63.16\%) undergoing deep excision. The average age was $36.89 \pm 15.42$ years, and $46.12 \%$ were male. Age and sex did not vary between superficial or deep excision groups, but more patients underwent deep excision among white patients, 86 (58.80\%) versus 180 (71.43\%), $p=0.0082$. Comorbidities such as diabetes, hypertension, smoking status, COPD, and steroid use were similar among both groups (Table 1 ).

The vast majority of operations were elective (98.50\%), and none were noted to be emergency operations (Table 2). Distribution among admission quarters was even between both groups. There were no differences between groups in

Table 1: Baseline demographics and comorbidities.

\begin{tabular}{|c|c|c|c|c|}
\hline Characteristic & $\begin{array}{l}\text { Total } \\
399\end{array}$ & $\begin{array}{l}\text { Superficial Excision } \\
14736.84 \%\end{array}$ & $\begin{array}{l}\text { Deep Excision } \\
25263.16 \%\end{array}$ & $p$ Value \\
\hline Age (years) & 36.8915 .42 & 34.9815 .29 & 38.0115 .43 & 0.0577 \\
\hline \multicolumn{5}{|l|}{ Sex } \\
\hline Male & $18446.12 \%$ & $6846.26 \%$ & $11646.03 \%$ & 0.965 \\
\hline Female & $21553.88 \%$ & $7953.74 \%$ & $13653.97 \%$ & 0.965 \\
\hline \multicolumn{5}{|l|}{ Race } \\
\hline White & $26666.67 \%$ & $8658.50 \%$ & $18071.43 \%$ & 0.0082 \\
\hline Black & $338.27 \%$ & $149.52 \%$ & $197.54 \%$ & 0.4876 \\
\hline Hispanic & $358.77 \%$ & $85.44 \%$ & $2710.71 \%$ & 0.0725 \\
\hline Unknown/not reported & $6416.04 \%$ & $32 \quad 21.77 \%$ & $3212.70 \%$ & 0.0172 \\
\hline \multicolumn{5}{|l|}{ Comorbidities } \\
\hline Wound infection & $20.50 \%$ & $0 \quad 0.00 \%$ & $20.79 \%$ & 0.5335 \\
\hline Diabetes & $246.02 \%$ & $106.80 \%$ & $145.56 \%$ & 0.6133 \\
\hline Current smoker & $8320.80 \%$ & $3423.13 \%$ & $4919.44 \%$ & 0.3817 \\
\hline No dyspnea & $39398.50 \%$ & $14598.64 \%$ & $24898.41 \%$ & 0.8575 \\
\hline COPD & $61.50 \%$ & $0 \quad 0.00 \%$ & $62.38 \%$ & 0.0894 \\
\hline HTN & $133.26 \%$ & $53.40 \%$ & $83.17 \%$ & 0.9021 \\
\hline Weight loss & $0 \quad 0.00 \%$ & $0 \quad 0.00 \%$ & $0 \quad 0.00 \%$ & 1 \\
\hline Steroid use & $61.50 \%$ & $32.04 \%$ & $31.19 \%$ & 0.6738 \\
\hline Independent & $39498.75 \%$ & $147100.00 \%$ & $24798.02 \%$ & 0.0857 \\
\hline ASA 3 or greater & $5914.79 \%$ & $2013.61 \%$ & $3915.48 \%$ & 0.6116 \\
\hline Body mass index $\left(\mathrm{kg} / \mathrm{m}^{\wedge} 2\right)$ & 28.457 .24 & 28.098 .1 & 28.666 .69 & 0.4723 \\
\hline
\end{tabular}


Table 2: Perioperative Variables.

\begin{tabular}{|c|c|c|c|c|}
\hline & $\begin{array}{l}\text { Total } \\
399\end{array}$ & $\begin{array}{l}\text { Superficial Excision } \\
14736.84 \%\end{array}$ & $\begin{array}{l}\text { Deep Excision } \\
25263.16 \%\end{array}$ & $p$ Value \\
\hline Elective operation & $39398.50 \%$ & 145 98.64\% & $24898.41 \%$ & 0.8575 \\
\hline Emergency case & $00.00 \%$ & $00.00 \%$ & $00.00 \%$ & 1 \\
\hline \multicolumn{5}{|l|}{ Admission quarter } \\
\hline 1 & $9323.31 \%$ & $3221.77 \%$ & $6124.21 \%$ & 0.5785 \\
\hline 2 & $10225.56 \%$ & $3926.53 \%$ & $6325.00 \%$ & 0.7353 \\
\hline 3 & $9824.56 \%$ & $3523.81 \%$ & $6325.00 \%$ & 0.7899 \\
\hline 4 & $10626.57 \%$ & $4127.89 \%$ & $6525.79 \%$ & 0.6473 \\
\hline \multicolumn{5}{|l|}{ Wound class } \\
\hline Clean & $29273.18 \%$ & $11175.51 \%$ & $18171.83 \%$ & 0.4229 \\
\hline Clean/Contaminated & $6516.29 \%$ & $1912.93 \%$ & $4618.25 \%$ & 0.1644 \\
\hline Contaminated & $133.26 \%$ & $53.40 \%$ & $83.17 \%$ & 0.9021 \\
\hline Dirty/Infected & $297.27 \%$ & $128.16 \%$ & $176.75 \%$ & 0.5989 \\
\hline \multicolumn{5}{|l|}{ Preoperative Labs } \\
\hline Sodium & 139.62 .5 & 139.22 .3 & 139.72 .6 & 0.1627 \\
\hline BUN & 13.44 .7 & 13.74 .5 & 13.24 .8 & 0.4898 \\
\hline Creatinine & 0.80 .2 & 0.80 .2 & 0.80 .2 & 0.8718 \\
\hline Albumin & 4.20 .6 & 4.20 .4 & 4.20 .4 & 0.3976 \\
\hline Bili & 0.60 .3 & 0.60 .3 & 0.60 .3 & 0.5181 \\
\hline AST & 22.431 .2 & 22.89 .4 & 22.212 .5 & 0.7966 \\
\hline ALP & 70.038 .3 & 67.120 .2 & 71.119 .1 & 0.3863 \\
\hline WBC & 7.71 .6 & 7.22 .7 & 8.02 .6 & 0.0355 \\
\hline $\mathrm{HCT}$ & 41.34 .0 & 41.14 .7 & 41.43 .6 & 0.5948 \\
\hline PLT & 263.270 .7 & 265.263 .0 & 262.369 .1 & 0.7623 \\
\hline PTT & 30.94 .8 & 30.54 .5 & 31.24 .6 & 0.5512 \\
\hline INR & 1.00 .1 & 1.00 .1 & 1.00 .1 & 0.266 \\
\hline
\end{tabular}

Table 3: Surgeon Specialty.

\begin{tabular}{|c|c|c|c|c|}
\hline & $\begin{array}{l}\text { Total } \\
399\end{array}$ & $\begin{array}{l}\text { Superficial Excision } \\
14736.84 \%\end{array}$ & $\begin{array}{l}\text { Deep Excision } \\
25263.16 \%\end{array}$ & $p$ Value \\
\hline \multicolumn{5}{|l|}{ Surgeon Specialty } \\
\hline General Surgery & $297.27 \%$ & $138.84 \%$ & $166.35 \%$ & 0.3546 \\
\hline Otolaryngology & $36491.23 \%$ & $13088.44 \%$ & $23492.86 \%$ & 0.132 \\
\hline Plastic Surgery & $51.25 \%$ & $42.72 \%$ & $10.40 \%$ & 0.0638 \\
\hline Vascular Surgery & $10.25 \%$ & $00.00 \%$ & $10.40 \%$ & 1 \\
\hline
\end{tabular}

rates of clean, clean/contaminated, contaminated, or dirty/ infected wound classifications. Values for preoperative labs were all clinically and statistically similar, except for white blood cell count, which was higher in the deep excision group (7.2 \pm 2.7 versus $8.0 \pm 2.6$ thousand/microliter) $(p=0.0355)$. Operations were most often performed by otolaryngology surgeons (91.23\%), though general, plastic, and vascular surgeons were represented. Rates of operations among the two groups by the specialists did not show statistical significance (Table 3).
The length of stay and time to the operation was not significantly different between the two groups (Table 4). Operative time was shorter in the superficial excision group compared to the deep excision group, $73 \pm 52$ versus $90 \pm 50$ minutes $(p=0.0013)$. All patients were discharged home. There was no observed 30-day mortality. Rates of technical complications were not statistically different between the two groups; however, the rate of readmission related to the initial operation was greater in the superficial group, 3 (2.04\%) versus $0(0 \%)(p=0.0494)$ (Table 5$)$. 
Table 4: Lesion Type.

\begin{tabular}{|l|l|l|l|l|}
\hline & $\begin{array}{l}\text { Total } \\
\text { 399 }\end{array}$ & $\begin{array}{l}\text { Superficial Excision } \\
\mathbf{1 4 7} \mathbf{3 6 . 8 4 \%}\end{array}$ & $\begin{array}{l}\text { Deep Excision } \\
\mathbf{2 5 2} \mathbf{6 3 . 1 6 \%}\end{array}$ \\
\hline Branchial Cleft Cyst, Sinus, Fistula & $33784.46 \%$ & $11477.55 \%$ & $22388.49 \%$ & 0.0036 \\
\hline Preauricular Cyst, Sinus, Fistula & $4010.03 \%$ & $2416.33 \%$ & $166.35 \%$ & 0.0014 \\
\hline Other Branchial Cleft Malformations & $225.51 \%$ & $96.12 \%$ & $135.16 \%$ & 0.6841 \\
\hline
\end{tabular}

Table 5: Perioperative Outcomes.

\begin{tabular}{|c|c|c|c|c|}
\hline & $\begin{array}{l}\text { Total } \\
399\end{array}$ & $\begin{array}{l}\text { Superficial Excision } \\
14736.84 \%\end{array}$ & $\begin{array}{l}\text { Deep Excision } \\
25263.16 \%\end{array}$ & $p$ Value \\
\hline Hospital days to operation & 0.091 .56 & 0.020 .14 & 0.131 .95 & 0.3729 \\
\hline Hospital length of stay (days) & 0.441 .73 & 0.270 .59 & 0.542 .13 & 0.0605 \\
\hline Operative time (minutes) & 8451 & 7352 & 9050 & 0.0013 \\
\hline 30-Day mortality & $00.00 \%$ & $00.00 \%$ & $00.00 \%$ & 1 \\
\hline Discharge destination (home) & $39899.75 \%$ & $147100.00 \%$ & $25199.60 \%$ & 0.4444 \\
\hline \multicolumn{5}{|l|}{ Complication } \\
\hline Readmission & $41.00 \%$ & $32.04 \%$ & $10.40 \%$ & 0.1436 \\
\hline Related to initial operation & $30.75 \%$ & $32.04 \%$ & $00.00 \%$ & 0.0494 \\
\hline Return to Operating Room & $20.50 \%$ & $21.36 \%$ & $00.00 \%$ & 0.1351 \\
\hline Related to initial operation & $20.50 \%$ & $21.36 \%$ & $00.00 \%$ & 0.1351 \\
\hline Unplanned intubation & $20.50 \%$ & $21.36 \%$ & $00.00 \%$ & 0.1351 \\
\hline On ventilator $>48$ hours & $00.00 \%$ & $00.00 \%$ & $00.00 \%$ & 1 \\
\hline Wound infection (superficial) & $10.25 \%$ & $10.68 \%$ & $00.00 \%$ & 0.3684 \\
\hline Wound infection (deep) & $20.50 \%$ & $21.36 \%$ & $00.00 \%$ & 0.1351 \\
\hline Organ space SSI & $00.00 \%$ & $00.00 \%$ & $00.00 \%$ & 1 \\
\hline Wound dehiscence & $00.00 \%$ & $00.00 \%$ & $00.00 \%$ & 1 \\
\hline Pneumonia & $00.00 \%$ & $00.00 \%$ & $00.00 \%$ & 1 \\
\hline Urinary tract infection & $00.00 \%$ & $00.00 \%$ & $00.00 \%$ & 1 \\
\hline DVT & $10.25 \%$ & $00.00 \%$ & $10.40 \%$ & 1 \\
\hline Pulmonary embolism & $00.00 \%$ & $00.00 \%$ & $00.00 \%$ & 1 \\
\hline Cardiac arrest requiring CPR & $00.00 \%$ & $00.00 \%$ & $00.00 \%$ & 1 \\
\hline Myocardial infarction & $00.00 \%$ & $00.00 \%$ & $00.00 \%$ & 1 \\
\hline Sepsis & $00.00 \%$ & $00.00 \%$ & $00.00 \%$ & 1 \\
\hline Shock & $00.00 \%$ & $00.00 \%$ & $00.00 \%$ & 1 \\
\hline Bleeding transfusion & $00.00 \%$ & $00.00 \%$ & $00.00 \%$ & 1 \\
\hline Renal complications & $00.00 \%$ & $00.00 \%$ & $00.00 \%$ & 1 \\
\hline
\end{tabular}

Table 6: Type of Lesion.

\begin{tabular}{|l|l|l|l|l|}
\hline & Total & Superficial Excision & Deep Excision & p Value \\
& $\mathbf{3 9 9}$ & $\mathbf{1 4 7} \mathbf{3 6 . 8 4 \%}$ & $\mathbf{2 5 2} \mathbf{6 3 . 1 6 \%}$ & \\
\hline Branchial cleft cyst, sinus, fistula & $33383.46 \%$ & $11276.19 \%$ & $22187.70 \%$ & 0.0028 \\
\hline Preauricular sinus or cyst & $4511.28 \%$ & $2718.37 \%$ & $187.14 \%$ & 0.0006 \\
\hline Other & $215.26 \%$ & $85.44 \%$ & $124.76 \%$ & 0.7639 \\
\hline
\end{tabular}

Superficial excisions were more likely to be performed on pre-auricular cysts or sinuses. In contrast, deep excisions were more likely to be performed on branchial cleft cysts, sinuses, or fistulas (Table 6).

\section{Discussion}

This analysis shows that adult patients undergoing surgical excision of branchial cleft malformations at ACS NSQIP 
participating hospitals may have similar short-term outcomes regardless of superficial or deep excision. While the length of operation may be longer in those undergoing deep excision, the clinical impact of this may be negligible. This analysis provides information for surgeons looking for national perioperative demographics and outcomes data of patients undergoing these procedures. This data also adds to the growing body of literature on pathologies, classically associated with children, which reach adulthood undetected.

This study may represent the largest cohort of patients undergoing branchial cleft excision as adults. The results support our hypothesis that patients undergoing deep excision of branchial cleft abnormalities may experience longer operative times, without apparent significant differences in clinical outcomes. Not captured in this data are outcomes relevant to the procedure and pathology, such as exact depth of involvement, preoperative episodes of infection, prior operations, or associated abnormalities. Postoperative pain and patient satisfaction are also not captured in this group. Finally, long term outcomes of recurrence or reoperation are not captured.

The strength of this study is the use of a national cohort of patients abstracted from the patient chart and not insurance claims, capturing procedures, surgeon specialty, and granular perioperative data and outcomes. We found little data on a national level, in the adult population, of patients undergoing such procedures for this pathology. Studies of the pediatric population involving national datasets are also scarce.

The study's limitations lie in its retrospective nature, the limitations inherent to the database, and the inherent differences surgical techniques among specialties. The ACS NSQIP database acknowledges several limitations inherent to their database [12]. Generic variables are collected, patients are only followed for 30 days, data is only from participating hospitals, and some variables are not present for each case. Further detail about case complexity, such as prior operations, is not available. Without a longer period of time tracking the patients, it is not possible to describe long term outcomes or disease recurrence and disease-free survival with this database. Data is only from participating hospitals, and neither surgical nor hospital volume are included as variables. Thus we are unable to control for these. Having these variables in such a database would allow for analysis and control of specialty volume and hospital volume. ACS NSQIP has worked to eliminate sampling error, but complete removal of bias is not possible without random assignment of cases by a computer-generated algorithm or similar mechanism. Although our study has several limitations, the database allows for analysis of trends on a more granular level than the National Inpatient Sample and avoids some of the biases that may be inherent in other databases as described by LaPar and colleagues [13].

Surgical treatment of branchial clefts in adults, while rare, appears to have low associated morbidity and little difference between superficial or deep excision. Operative time may be longer in the deep excision group, but the clinical impact of this may be small. This study equips surgeons with perioperative data of patients undergoing repair of these pathologies. Further research is necessary to study the pediatric to adult continuum of surgical pathology, including branchial cleft anomalies.

\section{Conclusion}

Little data exists about branchial cleft excision in the adult population regarding the demographics or perioperative outcomes. Furthermore, given the low rate of complications associated with branchial cleft excision, differences between surgical specialty, pathology, or procedural type can be difficult to distinguish. Based on analysis of the ACS NSQIP database from 2015 to 2018, branchial cleft excision is a safe procedure with little clinical difference between excision of superficial or deep lesions.

\section{Authors contribution}

Joseph G Brungardt: Conception and design of the work, collecting data, analysis, writing, reviewing and editing, final approval of manuscript.

Adam C Kahle: Writing, reviewing and editing, final approval of manuscript.

Kurt P Schropp: Final approval of manuscript, supervision.

All co-authors take full responsibility for all aspects of the study and the final manuscript.

\section{Acknowledgement}

American College of Surgeons National Surgical Quality Improvement Program and the hospitals participating in the ACS NSQIP are the source of the data used herein; they have not verified and are not responsible for the statistical validity of the data analysis or the conclusions derived by the authors.

\section{Declaration of Competing Interest}

The authors report no competing interests.

\section{Funding}

This research did not receive any specific grant from funding agencies in the public, commercial, or not-for-profit sectors.

\section{Competing Interest}

The authors have no disclosures or competing interest.

\section{Classifications}

Branchial cleft, sinus, excision, cyst, neoplasm.

\section{References}

1. Guldfred LA, Philipsen BB, Siim C (2012) Branchial cleft anomalies: Accuracy of pre-operative diagnosis, clinical presentation and management. J Laryngol Otol 126: 598-604.

2. Prosser JD, Myer IM (2015) Branchial cleft anomalies and thymic cysts. Otolaryngol Clin North Am 48: 1-14.

3. Goff CJ, Allred C, Glade RS (2012) Current management of congenital branchial cleft cysts, sinuses, and fistulae. Curr Opin Otolaryngol Head Neck Surg 20: 533-539.

4. Pynnonen MA, Gillespie MB, Roman B, et al. (2017) Clinical practice guideline: Evaluation of the neck mass in adults. Otolaryngol 
- Head Neck Surg 157:S1-S30.

5. Sira J, Makura ZGG (2011) Differential diagnosis of cystic neck lesions. Ann Otol Rhinol Laryngol 120: 409-413.

6. Goldenberg D, Begum S, Westra WH, et al. (2008) Cystic lymph node metastasis in patients with head and neck cancer: An HPV-associated phenomenon. Head Neck 30: 898-903.

7. Goldenberg D, Sciubba J, Koch WM (2006) Cystic metastasis from head and neck squamous cell cancer: A distinct disease variant? Head Neck 28: 633-638.

8. Robitschek J, Straub M, Wirtz E, et al. (2009) Diagnostic efficacy of surgeon-performed ultrasound-guided fine needle aspiration: A randomized controlled trial. Otolaryngol - Head Neck Surg 142: 306-309.
9. Lee DH, Yoon TM, Lee JK, et al. (2018) Clinical study of second branchial cleft anomalies. J Craniofac Surg 29: e557-e560.

10. Kadhim AL, Sheahan P, Colreavy MP, et al. (2004) Pearls and pitfalls in the management of branchial cyst. J Laryngol Otol 118: 946-950.

11. Bellakhdhar M, Haouas J, Abed W El, et al. (2018) Second branchial cleft cyst: About 34 cases. Tunisie Medicale 96: 888-892.

12. (2020) ACS NSQIP Participant use data file. American College of Surgeons.

13. LaPar DJ, Stukenborg GJ, Lau CL, et al. (2012) Differences in reported esophageal cancer resection outcomes between national clinical and administrative databases. J Thorac Cardiovasc Surg 144: 1152-1159. 